\title{
Elucidation of Analgesic Effects of Butorphanol Compared with Morphine: A Prospective Cohort Study
}

\author{
Dr. Rakesh Ranjan Singh \\ Associate Professor \\ Department of Anaesthesia, Katihar Medical College, Bihar, India \\ Dr. Ashmita Kiran \\ Assistant Professor \\ Department of Obstetrics and Gynaecology, Katihar Medical College, Bihar, India \\ Dr. Anant Narayan Sinha (Corresponding author) \\ Associate Professor, Department of Physiology \\ Veer Chandra Singh Garhwali Government Institute of Medical Science and Research \\ Srinagar, Uttarakhand (India) \\ E-mail: ansinha1973@yahoo.in
}

Received: May 3, 2015 Accepted: May 20, 2015

doi:10.5296/jbls.v6i2.7524 URL: http://dx.doi.org/10.5296/jbls.v6i2.7524

\begin{abstract}
Pain is a complex subjective experience comprising of both physical and emotional components. The International Association for the Study of Pain defines pain as "an unpleasant sensory and emotional experience associated with actual or potential tissue damage or described in terms of damage." Opioids are essentially important constituent of balanced anaesthesia. They provide adequate analgesia, reduces requirement of inhaled anaesthetic agents, maintain cardiovascular stability and provide adequate post-operative analgesia. Morphine remains the most widely used analgesic and the gold standard against which all new opioids are compared. Butorphanol has been employed successfully for the relief of postoperative pain, labor pain, preanaesthetic medication and in balanced anaesthesia.
\end{abstract}


We studied the analgesic property and the side effects of butorphanol and compared them with equipotent dose of morphine. This study revealed that butorphanol had more or less similar effects on haemodynamic parameters as compared to morphine. But butorphanol showed fewer side effects than morphine. This study suggested that patient compliance was on butorphanol.

Keywords: Analgesia, Blood pressure, Heart rate, Opioid

\section{Introduction}

Opioid acts as effective analgesics without resulting in loss of consciousness. Stimulation of opioid receptors $(\mu, \mathrm{K}, \delta)$ is solely responsible to mediate this response. These receptors are present mainly in brain and dorsal horn of spinal cord (Wagner., 2002).

The opioid receptors are coupled to G1 proteins and are in inhibitory in action. They seal $\mathrm{N}$-type voltage-operated calcium channels and open calcium-dependent inwardly-rectifying potassium channels leads to hyperpolarization and decreased neuronal excitability. They also decrease intracellular cAMP which modulates the release of nociceptive neurotransmitters (Bovill., 1997). Morphine, prototype opioid possesses high affinity for $\mu$ receptor acts as agonist and results in analgesia (Hall et al., 2001a). Adverse effect following morphine administration intravenously in dogs resulted in histamine release (Robinson et al., 1988)

Butorphanol is a synthetic opoid has emerged with its better efficacy and better safety profile. Its analgesic effect results from activation of $\mathrm{K}$ receptors (Monteiro et al., 2009). Conversely, butorphanol was found to have affinity for $\mu$ receptors where it acts as an antagonist. The analgesic efficacy of butorphnol is 3-5 times that of morphine (Wagner ., 2002).

This study was conducted to determine the potency of intravenous butorphanol in intra-operative and post-operative analgesia and to compare with that of morphine. We also compared the adverse effects of these drugs in immediate post-operative period.

\section{Material and Methods}

The study was conducted on 60 adult patients (18-60 years of age) of either gender, belonging to ASA grade-I or grade-II, weighing 45-70 kgs, posted for elective surgery under general anaesthesia. Informed consent was taken from all the patients. Ethics Committee clearance was obtained for this study.

\section{$\underline{\text { Exclusion criteria }}$}

A routine pre-anaesthetic examination of all the patients was done on the day prior to surgery. Patients with ventricular dysfunction, coronary insufficiency, valvular heart disease or hypertension, bronchial asthma and COPD, renal and / or hepatic pathology and head injury cases were excluded from the study. All patients were treated with diazepam $0.2 \mathrm{mg} / \mathrm{kg}$ orally at 10:00pm before surgery and at 7:00 am on the day of surgery.

\section{Procedure and anaesthetic techniques}

The Patients were randomly divided into 2 groups of 30 patients each. Patients in morphine 


\section{Macrothink

(control) group received $0.1 \mathrm{mg} / \mathrm{kg}$ of injection morphine sulphate IV and patients in butorphanol (study) group received $0.03 \mathrm{mg} / \mathrm{kg}$ of injection butorphanol tartrate IV, 10 minutes before induction. All the patients were preoxygenated for 3 minutes with $100 \%$ oxygen.

Patients were induced with sedative dose of injection thiopentone sodium (4-7 mg/Kg, 2.5\%) followed by injection suxamethonium chloride $2 \mathrm{mg} / \mathrm{kg}$ to facilitate endotracheal intubation. After 90 seconds of injection suxamethonium, laryngoscopy was performed and intubation was done with an appropriate sized cuffed endotracheal tube. Intubation time did not exceed 15 seconds. Patients were connected to mechanical ventilator with circle absorber system.

If there was any incidence of tachycardia, hypertension, lacrimation or diaphoresis, $1 / 4^{\text {th }}$ of initial dose of analgesic drug (morphine / butorphanol) was repeated during intraoperative period if surgery lasted for more than 4 hours.

Extubation was done in conscious state of patients. Patients were shifted to recovery room and monitored till the vitals were stable. Later patients were shifted to post-operative ward and monitored till 6 hours post-operatively.

\section{$\underline{\text { Recording of parameters }}$}

Heart rate, Systolic arterial pressure, diastolic arterial pressure and mean arterial pressure were recorded intra-operatively and post-operatively in both groups at various time intervals as follows:

Intra-operatively: Just before induction (base-line); at 1, 5, 30 and 60 minutes after intubation; at the end of surgery

Post-operatively: Immediately after extubation; Transferring from recovery room; at 2, 4 and 6 hours after extubation

\section{Statistical analysis}

Students't-test was used to compare mean and standard deviation of heart rate and blood pressure each group. The level of significance was set to $\mathrm{P}<0.05$.

\section{Results}

\section{Intra-operatively}

At the baseline heart rate, systolic arterial pressure (SAP), diastolic arterial pressure (DAP) and mean arterial pressure (MAP) were compared in both the groups. Significant increase in all haemodynamic parameters from the baseline recordings was seen at 1 minute after intubation. Heart rate and blood pressure (SAP, DAP \& MAP) were raised equally in both the groups. There was however no significant difference in the increase in the mean of haemodynamic parameters between the two groups at 1 minute after intubation (Fig: 1- Fig: 4). 


\section{Changes in HEARTRATE (HR)}
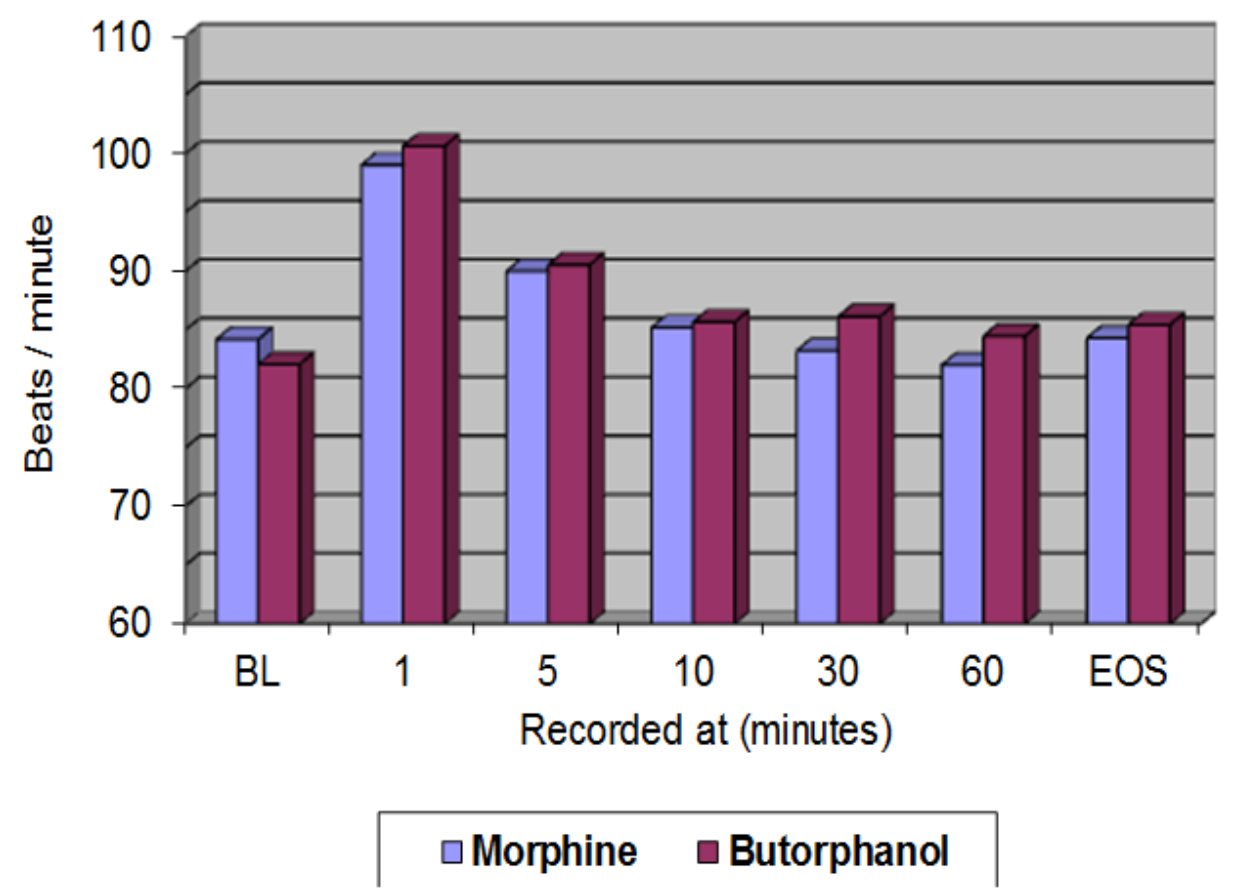

Figure 1.

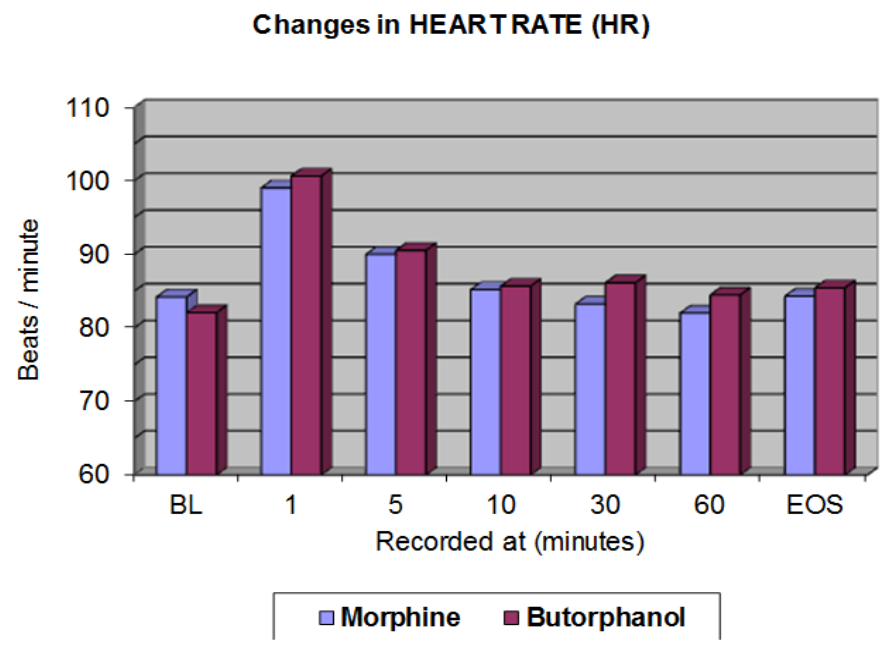

Figure 2. 
Changes in SYSTOLIC ARTERIAL PRESSURE (SAP)

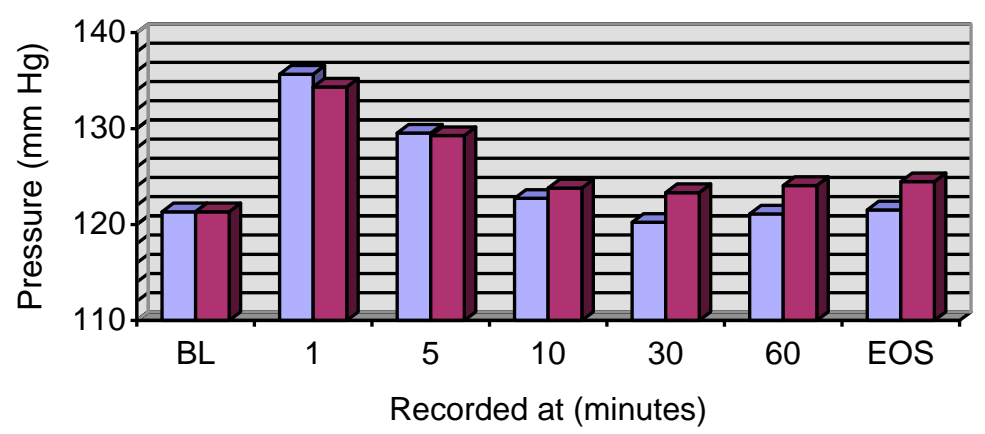

\section{$\square$ Morphine $\square$ Butorphanol}

Figure 3.

$\mathrm{BL}=$ Baseline; $\mathrm{EOS}=$ End of Surgery

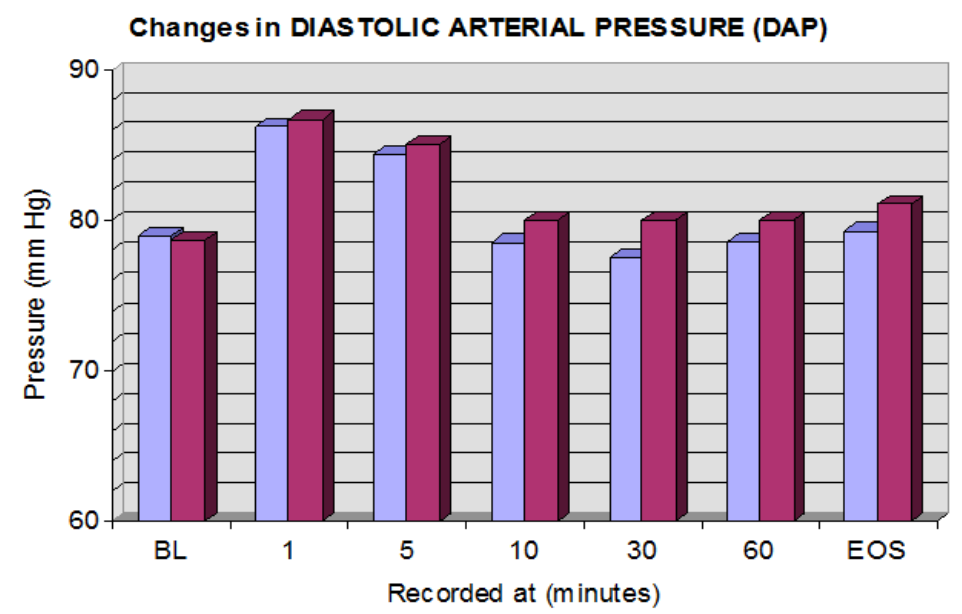

Figure 4.

Increase in haemodynamic parameters seen at 1 minute remained higher than the baseline but was statistically insignificant. By 10 minutes, all haemodynamic parameters returned to the baseline. There was no significant difference between the parameters in two groups either at 5 minutes or at 10 minutes (Fig: 1- Fig: 4).

No significant difference was observed in the mean of haemodynamic parameters between the two groups at 30 minutes, 60 minutes and at the end of surgery. All parameters in morphine group were marginally below the baseline values, whereas in butorphanol group they were marginally above the baseline (Fig: 1- Fig: 4).

\section{Post-operatively}

An increase in haemodynamic and parameters at extubation were observed from the baseline values in both the groups, but were statistically insignificant. All parameters were comparable in both the groups (Fig: 5- Fig: 8). 


\section{Macrothink}

Journal of Biology and Life Science

ISSN 2157-6076 2015, Vol. 6, No. 2

Depending on recovery and occurrence of side effects, patients were shifted from the recovery room to post-operative ward varying from 30-60 minutes after extubation. There was no significant difference in the mean of haemodynamic parameters in both the groups (Fig: 5- Fig: 8).

When compared with baseline, all haemodynamic parameters at transfer from recovery room, 2 hours, 4 hours and 6 hours in morphine group were marginally below the baseline values, whereas those in butorphanol group were marginally above the baseline. However these differences were statistically insignificant (Fig: 5- Fig: 8).

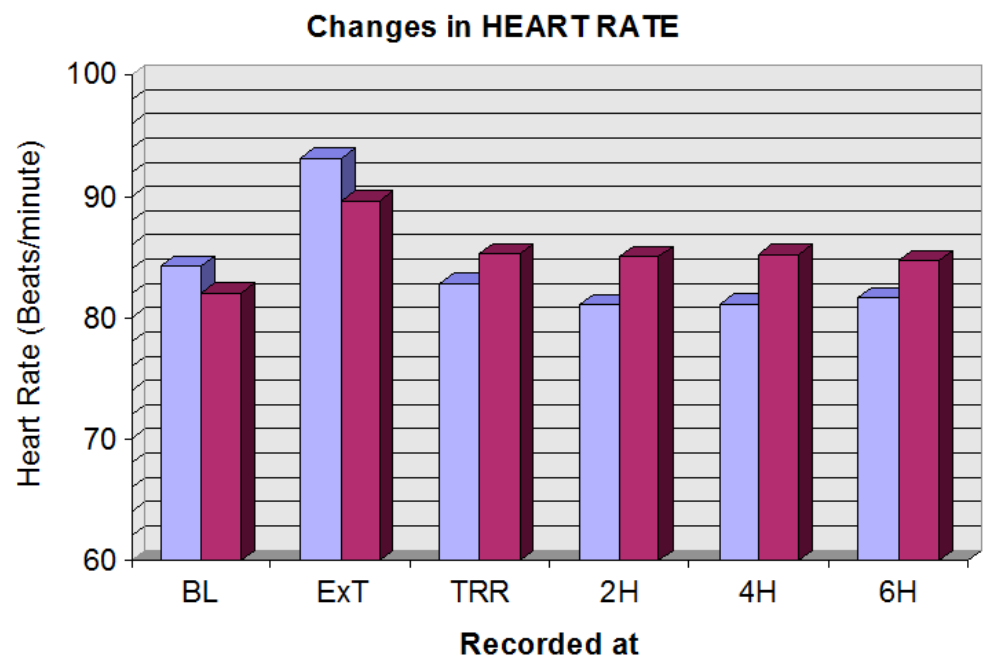

\section{$\square$ Morphine $\square$ Butorphanol}

Figure 5.

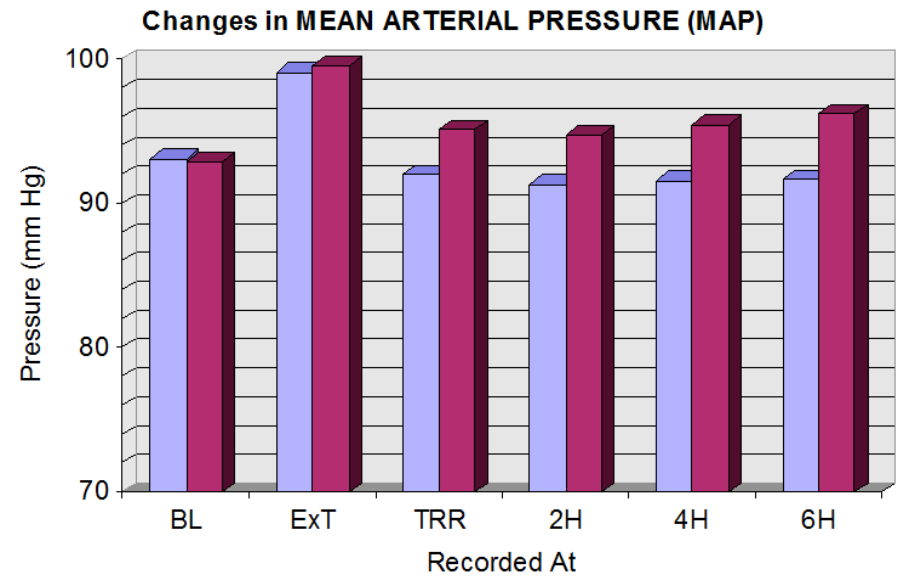

Figure 6. 


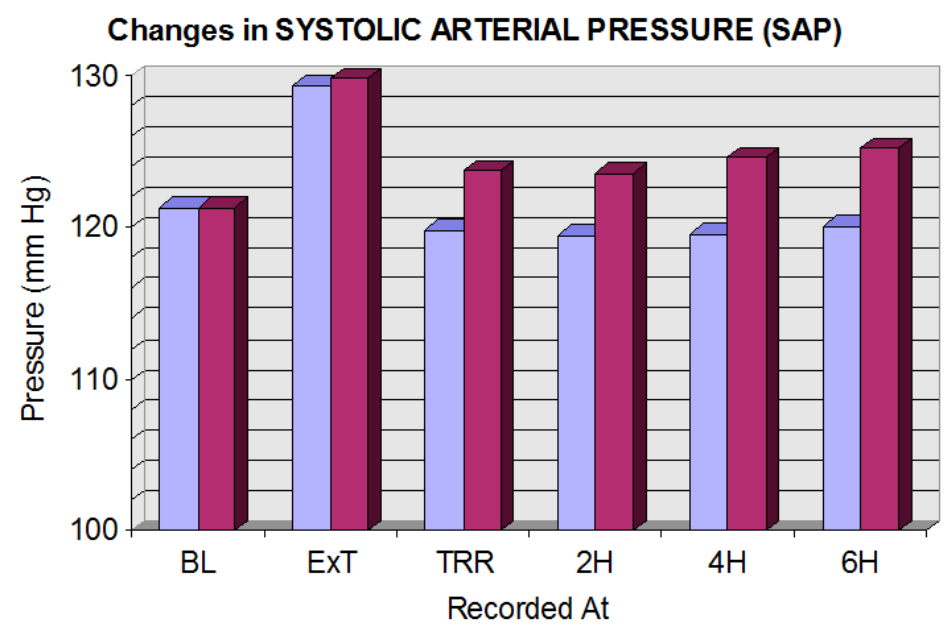

$\square$ Morphine $\square$ Butorphanol

Figure 7.

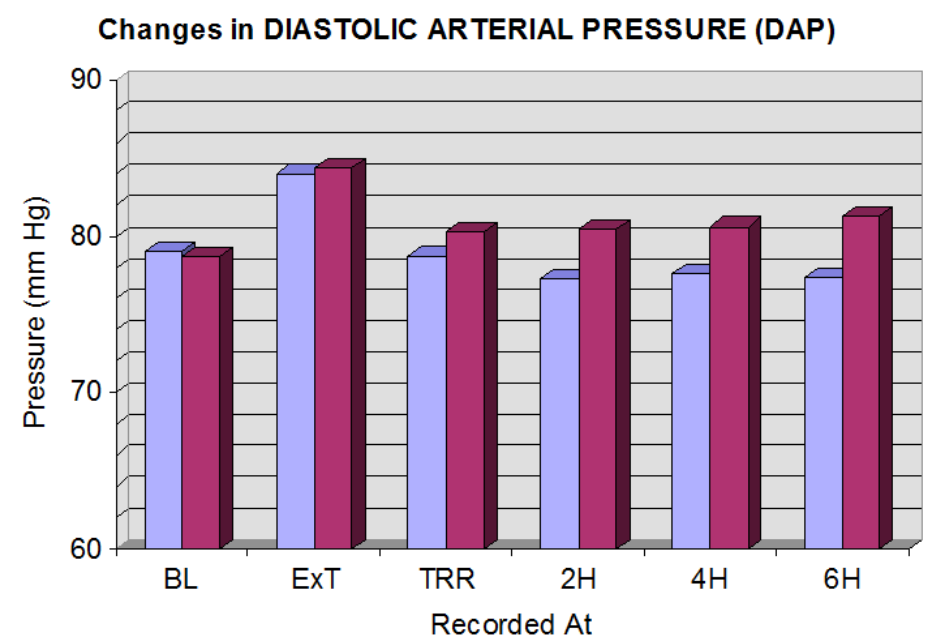

Figure 8.

Post-operative observations on adverse effects caused by morphine and butorphanol

The incidence of nausea and vomiting and post-operative shivering were not observed in butorphanol group whereas those in morphine group were $16.7 \%$ and $13.3 \%$ respectively. The incidence of sedation / somnolence was higher in butorphanol group (30\% v/s 6.7\%). These differences were statistically significant.

The incidence of respiratory depression was higher in morphine group (16.7\%) than that in butorphanol group $(6.7 \%)$ but it was statistically significant. Pruritus was not observed in any patient in either group. (Table: 1 ) 
Table 1. showing post-operative adverse effects caused by morphine and butorphanol

\begin{tabular}{|c|c|c|c|}
\hline Adverse effects & Morphine (n=30) & Butorphanol(n=30) & P value \\
\hline Post-operative Shivering & $04(13.3 \%)$ & Nil & $\mathrm{P}<0.05$ \\
\hline Nausea and / or Vomiting & $05(16.7 \%)$ & Nil & $\mathrm{P}<0.05$ \\
\hline Sedation / somnolence & $02(06.7 \%)$ & $09(30.0 \%)$ & $\mathrm{P}<0.05$ \\
\hline Respiratory depression & $08(26.7 \%)$ & $02(06.7 \%)$ & $\mathrm{P}<0.05$ \\
\hline
\end{tabular}

\section{Discussion}

Present study was performed to explore the intra-operative and post-operative analgesic effects of butorphanol and their post-operative side effects.

Walker et al investigated subjective, psychomotor, and physiological effects of cumulative doses of mixed-action opioids in healthy volunteers. Effects of all opioids were similar with some exceptions. Butorphanol had the strongest effects on psychomotor impairment and some subjective effects. Morphine was associated with delayed or prolonged side effects. Some effects of morphine were observed in this study that was not observed in the single-dosing studies (delayed / prolonged "unpleasant" effects, possible tachyphylaxis) (Walker., 2001).

A comparative study was performed to evaluate the direct effects and acute physical dependence of butorphanol and morphine, opioids with differing actions at $\mu$ versus $\kappa$ receptors. Butorphanol and morphine produced effects of comparable magnitude on miosis and reports of "any drug effect." Volunteers reported dysphoria, confusion and sedation after butorphanol, effects that overlapped with those of lorazepam. Morphine produced euphoria and stimulation (Greenwald and Stitzer., 1998).

Popio et al compared the haemodynamic and respiratory effects of morphine and butorphanol on twenty patients during diagnostic cardiac catheterization. Patients were given equipotent doses of either morphine sulphate $(0.125 \mathrm{mg} / \mathrm{Kg})$ or butorphanol tartrate $(0.025 \mathrm{mg} / \mathrm{Kg})$. Butorphanol decreased $\mathrm{pH}, \mathrm{pO}_{2}$, and systemic artery pressure and increased $\mathrm{pCO}_{2}$, cardiac index and pulmonary artery pressure. On contrary, morphine showed similar changes in $\mathrm{pH}$, $\mathrm{pO}_{2}$, systemic artery pressure and $\mathrm{pCO}_{2}$, but much smaller changes in cardiac index and no change in pulmonary artery pressure (Popio et al., 1978).

A double blind study was done on 50 patients. Patients were administrated with butorphanol tartrate $2.0 \mathrm{mg}$ or morphine sulphate $10 \mathrm{mg} 2$ to 3 minutes before induction of anaesthesia with sleep dose of thiopentone. The author has concluded that the analgesic action of butorphanol tartrate appeared in every respect to approximate that of morphine sulphate with negligible side effects (Del Pizzo., 1978).

Another double blind study compared effects of butorphanol and meperidine on maternal pain relief in labour. Butorphanol tartrate (1 \& $2 \mathrm{mg}$, IM) and meperidine (40 \& $80 \mathrm{mg}$, IM) were compared in 80 normal mothers. Butorphanol was found to be as effective as 
meperidine in relieving pain in labour (Maduska and Haagassemali., 1978).

Butorphanol (2 and $4 \mathrm{mg}$.) and pentazocine (60 mg.) were administered (IM) to the pateints. Butorphanol reached their peak in 30 minutes in contrast to 60 minutes for pentazocine. Analgesia was better in both butorphanol groups at $20 \& 30$ minutes than pentazocine. Side effects (sleep and dizziness) were noticed in $15 \%$ patients with no significant difference between the treatment groups (North and Tielens., 1979).

Morphine decreased the propulsion of charcoal meal through the gastrointestinal tract of mouse in a dose related manner with the maximum inhibition being $90 \%$ whereas butorphanol produced a maximal inhibition of motility of $40 \%$. In dogs, morphine caused a dose dependent increase in duodenal smooth muscle activity and a dose dependent decrease in bile duct flow, which was statistically significant with a dose of $0.1 \mathrm{mg} / \mathrm{Kg}$, while an equipotent dose of butorphanol $(0.025 \mathrm{mg} / \mathrm{Kg})$ had little or no effect on biliary or gastrointestinal systems. Butorphanol showed less constipation and less billiary tract or gastrointestinal smooth muscle spasm than morphine (Roebel et al., 1979).

Our observations were supported by Sung et al (1984) who compared morphine 0.3-0.6 $\mathrm{mg} / \mathrm{Kg}$ and butorphanol 0.06 to $0.1 \mathrm{mg} / \mathrm{Kg}$ in balanced anaesthesia and observed that vitals remained stable through the surgical procedure in both butorphanol and morphine group and that butorphanol have an analgesic action similar to that of morphine.

Tavakoli et al (1976) also compared post-operative analgesic effects of IM butorphanol tartrate $0.73 \mathrm{mg}$ ( $0.5 \mathrm{mg}$ base), $1.46 \mathrm{mg}$ ( $1 \mathrm{mg}$ base), or $2.92 \mathrm{mg}$ ( $2 \mathrm{mg}$ base), or morphine sulphate $5 \mathrm{mg}$ or $10 \mathrm{mg}$. and morphine on 127 patients. They found that heart rate \& blood pressure remained statistically similar in both the groups. These results were following the same direction with present study.

Our findings correlate with those of Laffey and Kay (1984) who compared effects of morphine $(10 \mathrm{mg}$ ) and butorphanol $(2 \mathrm{mg})$ on 40 patients undergoing hysterectomy. Quality of analgesia was assessed by open questioning.

\section{Conclusion}

Present study showed haemodynamic parameters in both the groups at 1 minute after intubation that remained high even at five minutes. This increase could be attributable to the adrenergic response due to laryngoscopy and intubation. During remaining intra-operative period all haemodynamic parameters were comparable between both the groups and within the group. An increase in haemodynamic parameters was observed in both groups at extubation. All haemodynamic parameters were comparable in both the groups and within the group during post-operative period. It showed that both the drugs provided adequate analgesia and cardiovascular stability both intra-operatively and post-operatively. But they did not abolish the adrenergic response due to laryngoscopy and intubation.

In our study, incidence of nausea and vomiting was high in morphine group than butorphanol group $(16.7 \% \mathrm{v} / \mathrm{s} 0 \%$ respectively). Incidence of post-operative shivering was also more in morphine than in butorphanol group $(13.3 \% \mathrm{v} / \mathrm{s} 0 \%$ respectively). Incidence of sedation or 
somnolence was significantly more in butorphanol group than morphine group $(30 \% \mathrm{v} / \mathrm{s}$ $6.7 \%$ respectively.

This study revealed that the quality and duration of analgesia provided by butorphanol was comparable to that of morphine during both intra-operative and post-operative period.

\section{References}

Bovill JG (1997). Mechanisms of actions of opioids and non-steroidal anti-inflammatory $\begin{array}{llllll}\text { drugs. } & \text { Eur } & J & \text { Anaesthesiol } & \text { Suppl. } & 15,\end{array}$ http://dx.doi.org/10.1097/00003643-199705001-00003

Del Pizzo A (1978). A double-blind study on the effect of butorphanol compared with morphine in balanced anesthesia. Can Anaesth Soe J. 25(5), 392-97. http://dx.doi.org/10.1007/BF03006568

Greenwald MK, Stitzer ML (1998). Butorphanol agonist effects and acute physical dependence in opioid abusers: comparison with morphine. Drug Alcohol Depend. 53(1), 17-30. http://dx.doi.org/10.1016/S0376-8716(98)00104-5

Hall LW, Clarke KW, Trim CM (2001a). Principles of sedation, analgesia and premedication. In: Veterinary Anaesthesia 10th edn. W.B.Saunders, London, UK. pp. 75-112. http://dx.doi.org/10.1016/B978-070202035-3.50005-X

Laffey D A, Kay N H (1984). Premedication with butorphanol. Br J Anaesth. 56, 363-67. http://dx.doi.org/10.1093/bja/56.4.363

Maduska A L, Haagassemali M. A double-blind comparison of butorphanol and meperidine in labour: maternal pain relief and effect on newborn. Can Anaesth Soc J. 25(5), 398-404. http://dx.doi.org/10.1007/BF03006569

Monteiro ER, Junior AR, Assis HMQ, Campagnol D, Quitzan JG (2009). Comparative study on the sedative effects of morphine, methadone, butorphanol or tramadol, in combination with acepromazine in dogs. Vet Anaesth Analg. 36(1), 25-33. http://dx.doi.org/10.1111/j.1467-2995.2008.00424.x

North W C, Tielens D R (1979). Comparison of butorphanol and pentazocine as postoperative $\begin{array}{lllll}\text { analgesics. } & \text { South } & \text { Med } & \text { J. } & \text { 72(5), }\end{array}$ http://dx.doi.org/10.1097/00007611-197905000-00020

Popio et al (1978). Hemodynamic and respiratory effects of morphine and butorphanol. Clinical Pharmacol and Ther. Vol. 23(3), 281-87.

Robinson EP, Faggella AM, Hardy DP, Russell WL (1988). Comparison of histamine release induced by morphine and oxymorphone administration in dogs. Am J Vet Res. 49, 1699-1701.

Roebel L E, Cavang R L, Buyniski J P (1979). Comparative gastrointestinal and biliary tract effects of morphine and butorphanol. J Med. 10(4), 225-38.

Sung Y F, Weinstein M S, Ghani G A (1984). "Balanced anesthesia: a comparison of 


\section{Macrothink}

Journal of Biology and Life Science

ISSN 2157-6076 2015, Vol. 6, No. 2

butorphanol and morphine." South Med J. 77(2), 180-82. http://dx.doi.org/10.1097/00007611-198402000-00013

Tavakoli M, Corrsen G, Caruso F S (1976). Butorphanol and morphine: a double blind comparison of their parentaral analgesic activity. Anesthesia \& Analgesia. Vol. 55: 394-401. http://dx.doi.org/10.1213/00000539-197605000-00025

Wagner AE (2002). Opioids. In: Handbook Veterinary Pain Management. Gaynor JS, Muir WW. Mosby, St Louis, USA. pp. 164-83.

Walker DJ, Zancy JP, Galva KE, Lichtor JL (2001). Subjective, psychomotor and physiological effects of cumulative doses of mixed-action opioids in healthy volunteers. Pharmacology. 155, 362-71. http://dx.doi.org/10.1007/s002130100723

\section{Copyright Disclaimer}

Copyright for this article is retained by the author(s), with first publication rights granted to the journal.

This is an open-access article distributed under the terms and conditions of the Creative Commons Attribution license (http://creativecommons.org/licenses/by/3.0/). 